
3 Research Square
Preprints are preliminary reports that have not undergone peer review.
They should not be considered conclusive, used to inform clinical practice,
or referenced by the media as validated information.

\title{
The Characteristics of Patients with Subsequent Distal Radius Fracture After Initial Distal Radius Fracture
}

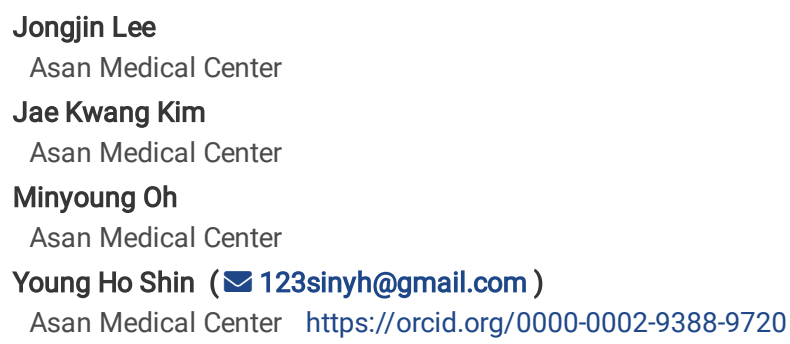

\section{Research article}

Keywords: Distal radius fracture, Subsequent Fracture, Bone mineral density, Hip geometry, Trabecular bone score, Bicortical thickness

Posted Date: September 18th, 2020

DOl: https://doi.org/10.21203/rs.3.rs-71478/v1

License: () (1) This work is licensed under a Creative Commons Attribution 4.0 International License. Read Full License 


\section{Abstract}

Background: The characteristics of patients who experienced subsequent distal radius fracture (DRF) after initial DRF have not been determined. The purpose of this study was to investigate the characteristics of patients with subsequent DRF and to compare bone fragility parameters of patients with primary and subsequent distal DRF.

Methods: We compared demographic characteristics and bone fragility parameters, including bone mineral densities (BMDs), trabecular bone score (TBS), hip geometry parameters, and bicortical thickness (BCT) of the distal radius in 215 patients with initial DRF and 26 patients with subsequent DRF. To reduce bias, patients with subsequent DRF were propensity score-matched in a 1:2 manner with patients affected by initial DRF, and additional comparison was performed.

Results: Patients in the subsequent DRF group were older than those in the initial DRF group, but this difference was not significant $(p=0.091)$. The proportion of patients receiving osteoporosis medications was significantly higher in the subsequent DRF group $(41.7 \%$ vs. $19.2 \%, p=0.011)$. Bone fragility parameters, including BMD, TBS, hip geometry parameters, and BCT did not differ significantly between the two groups. However, ten-year probability of major osteoporotic fractures was significantly higher in patients with subsequent DRF $(p<0.001)$. Similar results were observed upon comparing the propensity score-matched initial and subsequent DRF groups.

Conclusions: These findings suggest that the occurrence of subsequent DRF after initial DRF can be attributed to multiple factors rather than bone fragility alone. Systematic and multidisciplinary managements would be helpful for preventing the occurrence of subsequent DRF after initial DRF.

\section{Introduction}

The purpose of osteoporosis evaluation and management is to prevent the occurrence of osteoporotic fractures. This concept is most applicable to patients who have already experienced an osteoporotic fracture, as these patients are at higher risk of subsequent osteoporotic fracture [1,2]. Distal radius fracture (DRF) is the most common upper extremity fracture in women aged $\geq 50$ years [3], and the occurrence of DRF is considered indicative of bone fragility [2, 4]. The risk of future fractures at multiple sites, especially the hip and spine, has been reported to be higher in patients who have experienced wrist fracture than those who have not $[2,5-7]$. In addition, the wrist has been reported to be the most vulnerable site for subsequent fracture after initial wrist fracture, with the risk of subsequent wrist fracture being higher than the risk of hip fracture after an initial wrist fracture [6]. However, to date, the characteristics of patients with subsequent DRF after initial DRF have not been determined.

Bone mineral density (BMD) has been widely used for diagnosing bone fragility and is currently used as a parameter for diagnosing osteoporosis. However, because BMD does not always reflect fracture risk, other bone fragility parameters, such as trabecular bone score (TBS), hip geometry parameters, and cortical thickness of long bones, have been evaluated [8-10]. In addition, FRAX® was developed to reflect the clinical situation of the patients.

TBS, that provides an indirect index of trabecular bone, is less relevant to DRF [11]. Several hip geometry parameters, such as hip axis length (HAL, mm) and neck shaft angle (NSA, degree), are significantly associated with the development of hip fractures [12]. Moreover, the occurrence of DRF was significantly associated with decrease in the NSA and cross-sectional area (CSA, cm2) after adjusting for age, body mass index (BMI), and total hip BMD [13]. Bicortical thickness $(B C T)$ of the distal radius has been reported to correlate with hip BMDs, indicating that the biomechanical properties of these two appendicular skeletons are similar [14]. To our knowledge, these bone fragility parameters have not been evaluated in patients with subsequent DRF.

The present study was designed to investigate the characteristics of patients with subsequent DRF after initial DRF. In addition, bone fragility parameters were compared in patients with initial and subsequent distal radius fracture to identify the factors contributing to the occurrence of subsequent DRF.

\section{Materials And Methods Study Population}

The protocol used for this cross-sectional, retrospective review of medical records was approved by the institutional review board of our institute. We enrolled women who experienced a DRF between September 2016 and April 2019 and met the following inclusion criteria: (1) acute DRF caused by minor trauma, such as a fall from standing height, and (2) underwent a DXA scan (Lunar Prodigy; GE Lunar, WI) within two weeks after the fracture. Although our institute does not have a fracture liaison service, an osteoporosis examination is routinely recommended for all patients with DRF on their first follow-up visit to the outpatient clinic or after admission for operation. Finally, 227 women who met the criteria were enrolled. The mean age of the cohort was $65.1 \pm 10.1$ years, mean BMI was $23.4 \pm 3.1 \mathrm{~kg} / \mathrm{m}^{2}$, and 163 patients ( $71.8 \%$ of 227 patients) were treated surgically.

Among the 227 patients with DRF, 203 experienced a first time DRF (initial DRF group) and 24 had a previous history of DRF (subsequent DRF group). The demographic characteristics, osteoporosis treatment history, and bone fragility parameters, including BMD, TBS, hip geometry parameters, BCT of the distal radius, and FRAX scores, were compared between the two groups. To reduce bias, patients in the subsequent DRF group were propensity score matched at a $1: 2$ ratio with patients in the initial DRF group, and additional comparison was performed between these groups. The propensity score was calculated for each patient based on logistic regression analysis, using subject age, BMI, and sex for matching.

\section{BMDs and TBS}

At our institute, BMD $\left(\mathrm{g} / \mathrm{cm}^{2}\right)$ was measured in the lumbar spine, femoral neck, trochanter, Ward's triangle, and the total hip using Lunar Prodigy DXA scans (GE Healthcare, Madison, WI) and was analyzed using Encore Software ver.11.0. The lowest BMD T-score was derived from the BMDs of the lumbar spine, 
total hip, and femoral neck only, in accordance to the classification proposed by the World Health Organization [15]. Osteoporosis was defined as a lowest BMD T-score $<-2.5$. The BMD precision errors (percentage of the coefficient of variation)-measured by assessing 30 individuals with two scans at our institution-were $1.9 \%$ for the lumbar spine, $2.5 \%$ for the femoral neck, and $1.8 \%$ for the total hip. The least significant changes in BMD, calculated as $2.77 \times$ precision error and at a $95 \%$ confidence level, were $0.053 \mathrm{~g} / \mathrm{cm}^{2}$ for the lumbar spine, $0.069 \mathrm{~g} / \mathrm{cm}^{2}$ for the femoral neck, and $0.050 \mathrm{~g} / \mathrm{cm}^{2}$ for the total hip. For the lumbar spine BMD, the L1-4 value was used for analysis. All TBS measurements were performed retrospectively using TBS iNsight Software, ver. 3.02 (Med-Imaps, Needham, MA, USA) based on spine DXA files from the database to ensure that the investigators are blinded to all clinical parameters. The software uses the raw DXA images of the anteroposterior spine for the same region of interest as the lumbar spine BMD measurements.

\section{Hip geometry parameters}

Geometric bone structure properties in all scans were further analyzed using the advanced hip assessment (AHA) program included with the GE Lunar Prodigy software, as described previously $[16,17]$. The AHA program automatically set the region of interest, defined as the narrow neck (NN), transversing the narrowest width of the femoral neck. The AHA program yielded data for HAL, NSA, mean cortical thickness (mm), femur neck width (FNW, mm), CSA, crosssectional moment of inertia $\left(\mathrm{CSMI}, \mathrm{cm}^{4}\right)$, section modulus $\left(\mathrm{SM}, \mathrm{cm}^{3}\right)$, and buckling ratio $(\mathrm{BR})$ at the NN. The short-term coefficients of variance of AHA indices calculated from the images used for the precision assessment of BMD appeared to be slightly greater than those of conventional BMD, but were approximately $2 \%$, similar to the previously reported precision data [18].

\section{Cortical thickness of the distal radius}

Cortical bone thickness was measured and analyzed based on a previously described method of analyzing the relationship between the BMD and cortical thickness of the distal radius [14]. In patients with initial DRF or recurrent DRF on the same side, an image of the contralateral side was selected. In patients with subsequent DRF on the side contralateral to that of the previous DRF, an old DRF side image was selected. In patients with bilateral subsequent DRF, an image of the dominant hand was selected. All images were randomly sorted after removing the personal information of patients and were reviewed by one orthopedic surgeon and one orthopedic resident. All radiographic measurements were performed using the picture archiving and communication systems program of our institute (Petavision $\left.\AA_{1}, 000,000,000\right)$. Varying image magnification was normalized by standardizing longitudinal capitate lengths on all radiographs to $21.65 \mathrm{~mm}$ [19]. ВCT was measured 50 and $70 \mathrm{~mm}$ proximal to the distal radio-ulnar joint, with the mean of the two measurements defined as average BCT. The mean value of each measurement was used for the analysis.

\section{FRAX}

FRAX $\circledast$ is a simple Fracture Risk Assessment Tool developed by the World Health Organization. FRAX algorithms calculate the ten-year probability of major osteoporotic fractures and hip fractures. We calculated the ten-year probability of fracture by including clinical risk factors such as previous fracture, hip fracture in parents, smoking habits, use of steroid medicine, rheumatoid arthritis, secondary osteoporosis, and alcohol habits. FRAX scores were acquired using the web-based calculation tool for 000. We adjusted the FRAX score with TBS in each patient.

\section{Statistical analysis}

All statistical analyses, including propensity score matching analysis, were performed using the R statistical software (ver. 3.1.0; Foundation for Statistical Computing, Vienna, Austria; http://cran.r-project.org/), with $p<0.05$ considered significant. Descriptive statistics, including means and $95 \%$ confidence intervals, were estimated for both groups. After assessing the normality of the distribution of the tested parameters, between-group differences in continuous variables including demographic data, BMD, hip geometry parameters, cortical thickness of the distal radius, and ten year probability of osteoporotic fracture were assessed using the Student's $t$-test or Mann-Whitney U-test, as appropriate. Categorical variables, including the proportions of female patients and those with underlying diseases, were compared in the two groups using the chi-square test or Fisher's exact test. The reliability of measurements of distal radius BCT was calculated using the single measures intra-class correlation coefficient (ICC) from a two-way random effect ANOVA. Correlations between all parameters were evaluated using the Pearson correlation test. The correlation coefficient was interpreted using the scale proposed by Evans: $0.00-0.19$, very weak; $0.20-$ 0.39 , weak; $0.40-0.59$, moderate; $0.60-0.79$, strong; and $0.80-1.00$, very strong, respectively [20].

\section{Results}

\section{Characteristics of subsequent DRF patients}

The mean time from initial DRF to subsequent DRF was $121.5 \mathrm{mo} \pm 82.3 \mathrm{mo}$ (range, 1 to $240 \mathrm{mo}$ ). Of the 24 patients with subsequent DRF, 16 experienced recurrent DRF of the same wrist, seven had subsequent DRF on the contralateral side of the initial DRF, and one experienced bilateral DRF simultaneously after an initial unilateral DRF. Patients in the subsequent DRF group were older than those in the initial DRF group, but this difference was not significant ( $p=0.091)$. The portion of patients receiving osteoporosis medications was significantly higher in the subsequent than in the initial DRF group (41.7\% vs. $19.2 \%, p=$ 0.011). Other demographic factors and the proportions of patients with underlying diseases were similar in the two groups, except that the rate of asthma was significantly higher in the subsequent DRF group $(p=0.009)$ (Table 1$)$. 
Table 1

Baseline patient characteristics

\begin{tabular}{|c|c|c|c|}
\hline Variables & Primary DRF group $(n=203)$ & Subsequent DRF group $(n=24)$ & $p$-value \\
\hline Age (years) & $64.7 \pm 10.3$ & $68.4 \pm 8.2$ & 0.091 \\
\hline Body mass index $\left(\mathrm{kg} / \mathrm{m}^{2}\right)$ & $23.3 \pm 3.1$ & $23.4 \pm 3.1$ & 0.969 \\
\hline Hypertension & $85(41.9 \%)$ & $9(37.5 \%)$ & 0.681 \\
\hline Dyslipidemia & $84(41.4 \%)$ & $7(29.2 \%)$ & 0.248 \\
\hline Diabetes mellitus & $22(10.8 \%)$ & $3(12.5 \%)$ & 0.734 \\
\hline Stroke history & $12(5.9 \%)$ & $1(4.2 \%)$ & 0.999 \\
\hline Renal insufficiency & $7(3.4 \%)$ & $0(0.0 \%)$ & 0.999 \\
\hline Thyroid or parathyroid disease & $22(10.8 \%)$ & $2(8.3 \%)$ & 0.999 \\
\hline Rheumatoid arthritis & $9(4.4 \%)$ & $1(4.2 \%)$ & 0.999 \\
\hline Asthma & $5(2.5 \%)$ & $4(16.7 \%)$ & $0.009 *$ \\
\hline Malignancy & $21(10.3 \%)$ & $4(16.7 \%)$ & 0.314 \\
\hline Steroid medication history & $11(5.4 \%)$ & $0(0.0 \%)$ & 0.612 \\
\hline Proton pump inhibitor medication history & $10(4.9 \%)$ & $3(12.5 \%)$ & 0.146 \\
\hline Smoking history & $2(1.0 \%)$ & $0(0.0 \%)$ & 0.999 \\
\hline Osteoporosis medication history & $39(19.2 \%)$ & $10(41.7 \%)$ & $0.011^{*}$ \\
\hline Vitamin D medication history & $88(43.3 \%)$ & $11(45.8 \%)$ & 0.817 \\
\hline Calcium medication history & $24(11.8 \%)$ & $2(8.3 \%)$ & 0.999 \\
\hline \multicolumn{4}{|l|}{${ }^{\star} p<0.05$} \\
\hline \multicolumn{4}{|c|}{ Data are expressed as either mean \pm standard deviation or numbers (percentage) } \\
\hline DRF, distal radius fracture & & & \\
\hline
\end{tabular}

\section{Bone Fragility Parameters In Initial And Subsequent Drf Patients}

BMDs, TBS, hip geometry parameters, and BCT of the distal radius did not differ significantly in the initial and subsequent DRF groups. The lowest T-score in the DXA, along with BMDs and TBS, were higher-and the rate of osteoporosis was lower-in the subsequent DRF group than those in the initial DRF group. However, the ten-year probability of major osteoporotic fracture was significantly higher in patients with subsequent DRF ( $p<0.001)($ Table 2$)$. Similar results were observed when propensity score-matched patients with initial DRF and subsequent DRF were compared (Table 3). The ICC was 0.867 (95\% confidence interval: $0.828-0.897)$ for inter-observer reliability of distal radius BCT. 
Table 2

BMDs, TBS, hip geometry parameters, cortical thickness of the distal radius and ten year probability of osteoporotic fracture in patients with primary and subsequent distal radius fracture (DRF)

\begin{tabular}{|c|c|c|c|}
\hline Variables & Initial DRF group $(n=203)$ & Subsequent DRF group $(n=24)$ & $p$-value \\
\hline Lumbar BMD (g/cm²) & $0.910 \pm 0.145$ & $0.918 \pm 0.124$ & 0.682 \\
\hline Femur neck BMD (g/cm²) & $0.742 \pm 0.115$ & $0.748 \pm 0.108$ & 0.835 \\
\hline Trochanter BMD $\left(\mathrm{g} / \mathrm{cm}^{2}\right)$ & $0.618 \pm 0.103$ & $0.639 \pm 0.111$ & 0.369 \\
\hline Total hip BMD $\left(\mathrm{g} / \mathrm{cm}^{2}\right)$ & $0.790 \pm 0.116$ & $0.808 \pm 0.109$ & 0.456 \\
\hline Lowest T score in DXA & $-2.3 \pm 1.0$ & $-2.1 \pm 0.8$ & 0.351 \\
\hline Osteoporosis & $82(40.4 \%)$ & $7(29.2 \%)$ & 0.378 \\
\hline Trabecular bone score & $1.366 \pm 0.082$ & $1.367 \pm 0.090$ & 0.594 \\
\hline $\mathrm{HAL}(\mathrm{mm})$ & $100.9 \pm 5.1$ & $100.6 \pm 4.8$ & 0.762 \\
\hline NSA ( ) & $125.1 \pm 4.1$ & $125.5 \pm 3.3$ & 0.444 \\
\hline Cortical width (mm) & $4.6 \pm 1.5$ & $4.6 \pm 1.2$ & 0.663 \\
\hline $\operatorname{CSA}\left(\mathrm{cm}^{2}\right)$ & $108.3 \pm 17.3$ & $107.4 \pm 17.8$ & 0.795 \\
\hline $\operatorname{CSMI}\left(\mathrm{cm}^{4}\right)$ & $6969.5 \pm 1642.5$ & $6396.1 \pm 1624.3$ & 0.209 \\
\hline $\mathrm{SM}\left(\mathrm{cm}^{3}\right)$ & $421.1 \pm 87.7$ & $393.4 \pm 97.1$ & 0.149 \\
\hline BR & $4.1 \pm 1.6$ & $3.8 \pm 1.0$ & 0.580 \\
\hline Mean bicortical thickness of distal radius (mm) & $5.0 \pm 0.9$ & $5.1 \pm 0.8$ & 0.471 \\
\hline Ten year probability of major osteoporotic fracture on FRAX (\%) & $7.5 \pm 4.1$ & $10.8 \pm 4.3$ & $<0.001^{*}$ \\
\hline Ten year probability of hip fracture on FRAX (\%) & $2.5 \pm 2.7$ & $3.3 \pm 2.6$ & 0.050 \\
\hline \multicolumn{4}{|c|}{ Data are expressed as either mean \pm standard deviation or numbers (percentage) } \\
\hline$* p<0.05$ & & & \\
\hline
\end{tabular}


Table 3

BMDs, TBS, hip geometry parameters, cortical thickness of the distal radius and ten year probability of osteoporotic fracture in propensity score matched patients with primary and subsequent distal radius fracture (DRF)

\begin{tabular}{|c|c|c|c|}
\hline Variables & Initial DRF group $(n=48)$ & Subsequent DRF group $(n=24)$ & $p$-value \\
\hline Age (years) & $67.9 \pm 9.2$ & $68.4 \pm 8.2$ & 0.830 \\
\hline Body mass index $\left(\mathrm{kg} / \mathrm{m}^{2}\right)$ & $24.0 \pm 3.3$ & $23.4 \pm 3.1$ & 0.438 \\
\hline Lumbar BMD (g/cm²) & $0.913 \pm 0.135$ & $0.918 \pm 0.124$ & 0.877 \\
\hline Femur neck BMD (g/cm²) & $0.724 \pm 0.116$ & $0.748 \pm 0.108$ & 0.410 \\
\hline Trochanter BMD $\left(\mathrm{g} / \mathrm{cm}^{2}\right)$ & $0.613 \pm 0.103$ & $0.639 \pm 0.111$ & 0.334 \\
\hline Total hip BMD (g/cm²) & $0.771 \pm 0.121$ & $0.808 \pm 0.109$ & 0.212 \\
\hline Lowest T score in DXA & $-2.4 \pm 1.0$ & $-2.1 \pm 0.8$ & 0.290 \\
\hline Osteoporosis & $17(35.4 \%)$ & $7(29.2 \%)$ & 0.791 \\
\hline Trabecular bone score & $1.352 \pm 0.093$ & $1.367 \pm 0.090$ & 0.313 \\
\hline $\mathrm{HAL}(\mathrm{mm})$ & $101.1 \pm 5.1$ & $100.6 \pm 4.8$ & 0.538 \\
\hline NSA ( ) & $124.9 \pm 5.0$ & $125.5 \pm 3.3$ & 0.594 \\
\hline Cortical width (mm) & $4.6 \pm 1.7$ & $4.6 \pm 1.2$ & 0.684 \\
\hline $\mathrm{CSA}\left(\mathrm{cm}^{2}\right)$ & $106.6 \pm 17.2$ & $107.4 \pm 17.8$ & 0.856 \\
\hline $\operatorname{CSMI}\left(\mathrm{cm}^{4}\right)$ & $7018.2 \pm 1525.3$ & $6396.1 \pm 1624.3$ & 0.115 \\
\hline $\mathrm{SM}\left(\mathrm{cm}^{3}\right)$ & $419.0 \pm 77.1$ & $393.4 \pm 97.1$ & 0.227 \\
\hline BR & $4.3 \pm 2.1$ & $3.8 \pm 1.0$ & 0.459 \\
\hline Mean bicortical thickness of distal radius & $4.9 \pm 1.0$ & $5.1 \pm 0.8$ & 0.280 \\
\hline Ten year probability of major osteoporotic fracture on FRAX (\%) & $8.4 \pm 4.3$ & $10.8 \pm 4.3$ & $0.009 *$ \\
\hline Ten year probability of hip fracture on FRAX (\%) & $3.0 \pm 2.9$ & $3.3 \pm 2.6$ & 0.437 \\
\hline \multicolumn{4}{|c|}{ Data are expressed as either mean \pm standard deviation or numbers (percentage) } \\
\hline
\end{tabular}

Correlation between demographic variables, BMDs, TBS, hip geometry parameters, and bicortical thickness of the distal radius

The correlations among the parameters in the study population are described in Table 4. As expected, age and hip BMD were negatively correlated, whereas BMI was positively correlated with all BMDs. TBS $(r=-0.306, p<0.001), B C T(r=-0.504, p<0.001)$, and several hip geometry parameters, including CSA $(r=$ $-0.404, p<0.001)$, CSMI $(r=-0.306, p<0.001)$, and SM $(r=-0.365, p<0.001)$, showed significant negative correlations with age. The correlations between hip $\mathrm{BMD}$ and hip geometry parameters were consistent, with hip BMD being negatively correlated with NSA and BR, and positively correlated with cortical width, CSA, CSMI, and SM. BCT showed a moderate positive correlation with all BMDs, a weak positive correlation with TBS $(r=0.369, p<0.001)$, and positive correlations with several hip geometry parameters, including CSA $(r=0.444, p<0.001)$, CSMI $(r=0.250, p<0.001)$, and SM $(r=0.352, p<0.001)$. 
Table 4

Correlation coefficient $(r)$ between parameters in the study population

\begin{tabular}{|c|c|c|c|c|c|c|c|c|c|c|c|c|}
\hline & $\begin{array}{l}\text { Age } \\
\text { (years) }\end{array}$ & $\begin{array}{l}\text { BMI } \\
\left(\mathrm{kg} / \mathrm{m}^{2}\right)\end{array}$ & $\begin{array}{l}\text { Lumbar } \\
\text { BMD } \\
\left(\mathrm{g} / \mathrm{cm}^{2}\right)\end{array}$ & $\begin{array}{l}\text { Femur } \\
\text { neck } \\
\text { BMD } \\
\left(\mathrm{g} / \mathrm{cm}^{2}\right)\end{array}$ & $\begin{array}{l}\text { Trochanter } \\
\text { BMD } \\
\left(\mathrm{g} / \mathrm{cm}^{2}\right)\end{array}$ & $\begin{array}{l}\text { Total } \\
\text { hip } \\
\text { BMD } \\
\left(\mathrm{g} / \mathrm{cm}^{2}\right)\end{array}$ & $\begin{array}{l}\text { Trabecular } \\
\text { bone } \\
\text { score }\end{array}$ & $\begin{array}{l}\mathrm{HAL} \\
(\mathrm{mm})\end{array}$ & $\begin{array}{l}\text { NSA } \\
\text { (degrees) }\end{array}$ & $\begin{array}{l}\text { Cortical } \\
\text { width } \\
(\mathrm{mm})\end{array}$ & $\begin{array}{l}\text { CSA } \\
\left(\mathrm{cm}^{2}\right)\end{array}$ & $\begin{array}{l}\text { CSMI } \\
\left(\mathrm{cm}^{4}\right)\end{array}$ \\
\hline $\begin{array}{l}\text { BMI } \\
\left(\mathrm{kg} / \mathrm{m}^{2}\right)\end{array}$ & $0.169 \star \star$ & 1 & & & & & & & & & & \\
\hline $\begin{array}{l}\text { Lumbar } \\
\text { BMD } \\
\left(\mathrm{g} / \mathrm{cm}^{2}\right)\end{array}$ & -0.094 & $0.269 \star \star$ & 1 & & & & & & & & & \\
\hline $\begin{array}{l}\text { Femur } \\
\text { neck BMD } \\
\left(\mathrm{g} / \mathrm{cm}^{2}\right)\end{array}$ & $-0.426^{\star \star}$ & $0.207^{\star \star}$ & $0.535^{\star \star}$ & 1 & & & & & & & & \\
\hline $\begin{array}{l}\text { Trochanter } \\
\text { BMD } \\
\left(\mathrm{g} / \mathrm{cm}^{2}\right)\end{array}$ & $-0.267 \star \star *$ & $0.401^{\star *}$ & $0.518^{\star \star}$ & $0.813^{\star \star}$ & 1 & & & & & & & \\
\hline $\begin{array}{l}\text { Total hip } \\
\text { BMD } \\
\left(\mathrm{g} / \mathrm{cm}^{2}\right)\end{array}$ & $-0.355^{\star \star}$ & 0.330 ** & $0.562^{\star *}$ & $0.912^{\star \star}$ & $0.928^{\star \star}$ & 1 & & & & & & \\
\hline $\begin{array}{l}\text { Trabecular } \\
\text { bone } \\
\text { score }\end{array}$ & $-0.306^{\star \star}$ & $0.147^{*}$ & $0.338^{\star *}$ & $0.479 \star \star$ & $0.372^{\star \star}$ & $0.451 * \star$ & 1 & & & & & \\
\hline HAL (mm) & $-0.145^{\star}$ & 0.040 & 0.028 & -0.039 & -0.024 & -0.103 & -0.019 & 1 & & & & \\
\hline $\begin{array}{l}\text { NSA } \\
\text { (degrees) }\end{array}$ & -0.066 & $0.154^{*}$ & 0.048 & -0.066 & 0.003 & -0.074 & -0.036 & 0.099 & 1 & & & \\
\hline $\begin{array}{l}\text { Cortical } \\
\text { width } \\
(\mathrm{mm})\end{array}$ & -0.057 & 0.067 & 0.107 & $0.259 * \star$ & $0.271^{\star *}$ & $0.299 * \star$ & 0.096 & -0.074 & $0.139 *$ & 1 & & \\
\hline $\operatorname{CSA}\left(\mathrm{cm}^{2}\right)$ & $-0.404^{\star \star}$ & $0.217^{\star \star}$ & $0.518^{\star \star}$ & $0.881^{\star *}$ & $0.757 * \star$ & $0.795^{\star \star}$ & $0.453^{\star \star}$ & $0.157^{*}$ & -0.047 & $0.254^{\star \star}$ & 1 & \\
\hline $\begin{array}{l}\text { CSMI } \\
\left(\mathrm{cm}^{4}\right)\end{array}$ & $-0.306^{\star *}$ & 0.084 & $0.333^{\star \star}$ & $0.429 \star \star$ & $0.368^{\star \star}$ & $0.349 * \star$ & $0.259 * \star$ & $0.411^{\star *}$ & 0.035 & 0.063 & $0.747^{\star \star}$ & 1 \\
\hline $\mathrm{SM}\left(\mathrm{cm}^{3}\right)$ & $-0.365^{\star \star}$ & 0.103 & $0.414^{\star \star}$ & 0.650 ** & $0.522^{\star \star}$ & $0.550^{\star \star}$ & $0.331^{\star *}$ & $0.283^{\star \star}$ & -0.028 & 0.115 & $0.858 * \star$ & 0.918 ** \\
\hline BR & 0.059 & -0.029 & -0.130 & $-0.367 \star \star$ & $-0.343^{\star \star}$ & -0.401 ** & $-0.130 *$ & 0.200 ** & $0.178^{\star \star}$ & $-0.847 * \star$ & $-0.262^{\star \star}$ & 0.086 \\
\hline $\begin{array}{l}\text { Bicortical } \\
\text { thickness } \\
\text { of distal } \\
\text { radius } \\
(\mathrm{mm})\end{array}$ & -0.504 ** & 0.060 & $0.420 \star \star$ & $0.515^{\star \star}$ & $0.458^{\star \star}$ & $0.551^{\star *}$ & $0.369 * *$ & -0.034 & -0.008 & 0.120 & $0.444^{\star \star}$ & 0.250 ** \\
\hline${ }^{\star} p<0.05$, ** & 0.001 & & & & & & & & & & & \\
\hline
\end{tabular}

\section{Discussion}

Understanding the characteristics of patients who experience subsequent fragility fractures after initial fragility fractures is necessary to prevent these recurrent fractures. Several studies have evaluated the characteristics of patients who experienced subsequent fractures at other body sites. An evaluation of patients who experienced subsequent hip fracture after initial hip fracture revealed that older age, cognitive impairment, and lower bone mass may increase the risk of subsequent hip fracture [21]. In addition, subsequent vertebral fracture after initial vertebral fracture was associated with pre-existing vertebral deformities, vertebroplasty, and the location of the initial compression fracture [22-24]. The present study showed that bone fragility parameters, including BMDs, TBS, hip geometry parameters, and BCT of the distal radius, did not differ significantly between patients with initial and subsequent DRF, with similar results being observed after propensity score matching.

All subsequent DRFs occurred after minor trauma like initial DRFs, but the characteristics of the initial and subsequent DRFs differed. The age distribution and the periods between initial and subsequent DRF ranged widely in these groups, indicating their heterogeneity. Despite the fact that bone fragility parameters are not significantly different between the two groups and the percentage of patients exposed to osteoporosis medications being significantly higher in the subsequent than in the initial DRF group, the ten-year probability of developing major osteoporotic fractures was significantly higher in the subsequent DRF group. These findings indicate that the occurrence of subsequent DRF could dependent on multiple factors rather than those associated with bone fragility alone. Alternatively, bone fragility parameters, especially BMDs, may be improved by osteoporosis medications after initial DRF, but other uncorrected or uncorrectable factors may be associated with the development of subsequent DRF.

Factors that may be associated with subsequent DRF include physical performance level, risk of falling, and sarcopenia, all of which are highly related to the occurrence of initial DRF and cannot be evaluated using bone fragility parameters [25-27]. Muscle strengthening exercises for achieving high physical 
performance levels and slowing down during ambulation for reducing fall risk could be helpful for reducing the instances of subsequent DRF [25, 27]. Considering the fact that time from initial to subsequent DRF was varied and long, long-term care and lifestyle modification would be important for preventing subsequent DRF. The fracture liaison service (FLS), which provides systematic and multidisciplinary management for patients with fractures, including physical therapy, and education regarding diet and exercise, and osteoporosis management, would be an important option. Several studies have already revealed that FLS significantly reduces the incidence of subsequent fractures after initial fragility fracture [28-30].

The correlations between parameters in this study are similar to those previously reported in patients with DRF. For example, BMDs, TBS, BCT, and several parameters associated with hip geometry were negatively correlated with age $[11,12,18]$. The correlation coefficients between TBS and lumbar/total hip BMD were similar to those reported by a previous study [11]. Hip geometry parameters exhibited stronger correlations with hip BMDs than with lumbar BMDs [13]. In addition, the correlation coefficients between BCT and hip BMDs were similar to those reported previously [14]. Although the number of enrolled patients was smaller in this study than in other large cohort studies, these similar characteristics indirectly confirm the validity of these results.

This study has several limitations. First, its retrospective design limited its ability to prove causality for the occurrence of subsequent DRF. In addition, we could not evaluate other factors that may be related to the occurrence of subsequent DRF, such as physical performance level, risk of falling, and sarcopenia. A prospective observational study would be more suitable, but the time from initial to subsequent DRF was long and variable, and the incidence of subsequent DRF was not high. Thus, collecting a sufficient number of patients with detailed information would be difficult. Second, our institution is a tertiary referral hospital; thus, these subjects may be more diseased or injured than those in other institutions. Third, all study subjects were of 000 ethnicity. Because some hip geometry parameters, including HAL and NSA, vary according to ethnicity, the results cannot be extrapolated to other populations [12]. Finally, although we used propensity score matching to overcome the imbalances between the two groups, only 24 patients had experienced subsequent DRF, a much smaller number than the 215 for patients with initial DRF.

In conclusion, patients with subsequent DRF showed heterogeneity with respect to the age distribution and time interval between initial and subsequent DRF. Bone fragility parameters did not differ significantly between patients with initial and subsequent DRF, but the ten-year probability of being affected by a major osteoporotic fracture was significantly higher in patients with subsequent DRF. These findings suggest that the occurrence of subsequent DRF after initial DRF can be attributed to multiple factors rather than bone fragility alone. Systematic and multidisciplinary managements such as FLS would be helpful for preventing the occurrence of subsequent DRF after initial DRF.

\section{Declarations}

Ethics approval and consent to participate: This study was approved by the institutional review board of Asan Medical Center (2019-0686) and informed consent was waived.

Consent for publication: Not applicable.

Availability of data and materials: The raw data and materials are not available to the public.

Competing interests: Jongjin Lee, Jae Kwang Kim, Minyoung Oh, and Young Ho Shin declare that they have no conflict of interest.

Funding: This study was supported by a research fund (20201T0001-1) from Asan Institute for Life Science, Asan Medical Center, Republic of Korea.

Authors' contributions: Jongjin Lee and Young Ho Shin designed this study. Jongjin Lee and Minyoung Oh performed data collection and analysis. Jongjin Lee, Jae Kwang Kim and Young Ho Shin wrote the manuscript.

Acknowledgements: Not applicable

\section{References}

1. Balasubramanian A, Zhang J, Chen L, Wenkert D, Daigle SG, Grauer A, et al. Risk of subsequent fracture after prior fracture among older women. Osteoporos Int. 2019;30:79-92.

2. Haentjens P, Autier P, Collins J, Velkeniers B, Vanderschueren D, Boonen S. Colles fracture, spine fracture, and subsequent risk of hip fracture in men and women. A meta-analysis. J Bone Joint Surg Am. 2003;85:1936-43.

3. Chung KC, Shauver MJ, Birkmeyer JD. Trends in the United States in the treatment of distal radial fractures in the elderly. J Bone Joint Surg Am. 2009;91:1868-73.

4. Nevitt MC, Cummings SR, Stone KL, Palermo L, Black DM, Bauer DC, et al. Risk factors for a first-incident radiographic vertebral fracture in women $\geq 65$ years of age: the study of osteoporotic fractures. J Bone Miner Res. 2005;20:131-40.

5. Crandall CJ, Hovey KM, Cauley JA, Andrews CA, Curtis JR, Wactawski-Wende J, et al. Wrist fracture and risk of subsequent fracture: Findings from the women's health initiative study. J Bone Miner Res. 2015;30:2086-95.

6. Barrett-Connor E, Sajjan SG, Siris ES, Miller PD, Chen YT, Markson LE. Wrist fracture as a predictor of future fractures in younger versus older postmenopausal women: results from the National Osteoporosis Risk Assessment (NORA). Osteoporos Int. 2008;19:607-13.

7. Shin YH, Hong WK, Kim J, Gong HS. Osteoporosis care after distal radius fracture reduces subsequent hip or spine fractures: a 4-year longitudinal study. Osteoporos Int. 2020;31:1471-6. 
8. Schuit SC, van der Klift M, Weel AE, de Laet CE, Burger H, Seeman E, et al. Fracture incidence and association with bone mineral density in elderly men and women: the Rotterdam Study. Bone. 2004;34:195-202.

9. Nguyen BN, Hoshino H, Togawa D, Matsuyama Y. Cortical thickness index of the proximal femur: a radiographic parameter for preliminary assessment of bone mineral density and osteoporosis status in the age 50 years and over population. Clin Orthop Surg. 2018;10:149-56.

10. Shah GM, Gong HS, Chae YJ, Kim YS, Kim J, Baek GH. Evaluation and management of osteoporosis and sarcopenia in patients with distal radius fractures. Clin Orthop Surg. 2020;12:9-21.

11. Shin YH, Gong HS, Gang DH, Shin HS, Kim J, Baek GH. Evaluation of trabecular bone score in patients with a distal radius fracture. Osteoporos Int. 2016;27:3559-65.

12. Broy SB, Cauley JA, Lewiecki ME, Schousboe JT, Shepherd JA, Leslie WD. Fracture risk prediction by non-BMD DXA measures: the 2015 ISCD official positions part 1: hip geometry. J Clin Densitom. 2015;18:287-308.

13. Shin YH, Gong HS, Kim KM, Lee JH, Kwon O, Baek GH. Evaluation of hip geometry parameters in patients with a distal radius fracture. J Clin Densitom. 2019. doi:10.1016/j.jocd.2019.06.001.

14. Webber T, Patel SP, Pensak M, Fajolu O, Rozental TD, Wolf JM. Correlation between distal radial cortical thickness and bone mineral density. J Hand Surg Am. 2015;40:493-9.

15. World Health Organization. Assessment of fracture risk and its application to screening for postmenopausal osteoporosis. Report of a WHO Study Group. World Health Organ Tech Rep Ser. 1994;843:1-129.

16. Uusi-Rasi K, Semanick LM, Zanchetta JR, Bogado CE, Eriksen EF, Sato M, et al. Effects of teriparatide [rhPTH (1-34)] treatment on structural geometry of the proximal femur in elderly osteoporotic women. Bone. 2005;36:948-58.

17. Beck TJ, Looker AC, Ruff CB, Sievanen H, Wahner HW. Structural trends in the aging femoral neck and proximal shaft: analysis of the Third National Health and Nutrition Examination Survey dual-energy X-ray absorptiometry data. J Bone Miner Res. 2000;15:2297-304.

18. Kim KM, Lim JS, Kim KJ, Choi HS, Rhee Y, Oh HJ, et al. Dissimilarity of femur aging in men and women from a Nationwide Survey in Korea (KNHANES IV). J Bone Miner Metab. 2013;31:144-52.

19. Schuind FA, Linscheid RL, An KN, Chao EY. A normal data base of posteroanterior roentgenographic measurements of the wrist. J Bone Joint Surg Am. 1992;74:1418-29.

20. Evans JD. Straightforward statistics for the behavioral sciences. Pacific Grove: Brooks/Cole Pub. Co.; 1996.

21. Egan M, Jaglal S, Byrne K, Wells J, Stolee P. Factors associated with a second hip fracture: a systematic review. Clin Rehabil. 2008;22:272-82.

22. Lunt M, O'Neill TW, Felsenberg D, Reeve J, Kanis JA, Cooper C, et al. Characteristics of a prevalent vertebral deformity predict subsequent vertebral fracture: results from the European Prospective Osteoporosis Study (EPOS). Bone. 2003;33:505-13.

23. Lee KA, Hong SJ, Lee S, Cha IH, Kim BH, Kang EY. Analysis of adjacent fracture after percutaneous vertebroplasty: does intradiscal cement leakage really increase the risk of adjacent vertebral fracture? Skeletal Radiol. 2011;40:1537-42.

24. Han SL, Wan SL, Li QT, Xu DT, Zang HM, Chen NJ, et al. Is vertebroplasty a risk factor for subsequent vertebral fracture, meta-analysis of published evidence? Osteoporos Int. 2015;26:113-22.

25. Kelsey JL, Prill MM, Keegan TH, Tanner HE, Bernstein AL, Quesenberry CP Jr, et al. Reducing the risk for distal forearm fracture: preserve bone mass, slow down, and don't fall! Osteoporos Int. 2005;16:681-90.

26. Janssen I, Heymsfield SB, Ross R. Low relative skeletal muscle mass (sarcopenia) in older persons is associated with functional impairment and physical disability. J Am Geriatr Soc. 2002;50:889-96.

27. Cho YJ, Gong HS, Song CH, Lee YH, Baek GH. Evaluation of physical performance level as a fall risk factor in women with a distal radial fracture. J Bone Joint Surg Am. 2014;96:361-5.

28. Pflimlin A, Gournay A, Delabriere I, Chantelot C, Puisieux F, Cortet B, et al. Secondary prevention of osteoporotic fractures: evaluation of the Lille University Hospital's Fracture Liaison Service between January 2016 and January 2018. Osteoporos Int. 2019;30:1779-88.

29. Nakayama A, Major G, Holliday E, Attia J, Bogduk N. Evidence of effectiveness of a fracture liaison service to reduce the re-fracture rate. Osteoporos Int. 2016;27:873-9.

30. Axelsson KF, Jacobsson R, Lund D, Lorentzon M. Effectiveness of a minimal resource fracture liaison service. Osteoporos Int. 2016;27:3165-75. 